when shooting at a target on a range, but his practice may be very different when he is called upon to fire over the top of a trench at masses of an advancing enemy a hundred yards away. Experience shows that many defectives do well under the routine and discipline of a prison or other institution, but prove quite incapable of managing their affairs if called upon to face life on their own responsibility.

Unfortunately there is a tendency to regard mental defect from a much too restricted point of view, and to be too much influenced by one set of factors only. The eugenist finds sufficient evidence in the presence of a morbid family history; the follower of Lombroso in stigmata of degeneracy; the sociologist in anti-social conduct; the psychologist in failure to pass certain tests. In the matter of diagnosis one might almost say that this generation asks for a sign, for an automatic register, an infallible penny-in-the-slot machine-there is no such sign.

Mental deficiency is a symptom of imperfect or arrested development of mind, which may not only be due to many causes, but which may be simulated by many conditions. 'The diagnosis of the milder degrees requires keen observation, ample experience, and very considerable medical knowledge ; and whilst giving due attention to all the above data, there is no condition in which it is more necessary that the case should be considered in all its bearings. It is far from my intention to decry the use of psychological tests, of which, indeed, I make constant use, but the experienced physician will usually be able to come to a conclusion without any elaborate series of tests, and the inexperienced will probably fail in his diagnosis with them.

$$
\text { I am, Sir, yours faithfully, }
$$

A. F. TREdGoLd, M.D.

New Cavendish-street, W, Nov, 6th, 1920.

\section{THE PRESENT POSITION OF MIDWIFERY.} To the Eator of THE LANCET.

SIR,-I have read with great pleasure and profit Mr. Victor Bonney's charming address at Norwich. But there is just one point which has puzzled me. After calling attention to the problem of intrinsic infection and enforcing the necessity of sterilising the birth area, he goes the length of teaching that in cases of instrumental delivery a pad soaked in one of the modern antiseptics should be stitched over the anus so as to exclude all bowel organisms. With one's mind fixed on the dangers of the anal region, one experiences a mental shock when he calls attention to Eardley Holland's teaching that the presentation and degree of dilatation of the cervix could be well detected by rectal examination. Which is the safer proceeding-to learn the presentation per vaginam or per rectum? I am, Sir, yours faithfully,

Exeter, Nov, 7th, 1920. J. Pereira Gray.

THE HEREDITARY FACTOR IN TUBERCULOSIS To the Editor of THE LANCET.

SIR,-Apart from the theoretical interest of what is meant by the term " inherited diathesis," the recently published papers of Professor S. L. Cummins upon racial differences in susceptibility to tuberculosis raise a point of great importance. According to Professor Cummins's argument, the Native Labour Corps working in France succumbed very readily to tuberculosis because they were comparatively virgin soil, and thus acquired resistance is the essential factor in warding off the disease. Prevention of tuberculosis therefore depends not so much on environment, but on gradually building up the resistance of the individual by infection with doses of tubercle bacilli insufflcient at any one time to cause actual disease. Professor Cummins concludes that immunity is the way by which prevention of tuberculosis must be achieved, and suggests the possibility of accomplishing this by means of artificial vaccination.

The practical application of this theory is both of extreme interest and of great importance to the State. If virgin soil is the factor of paramount importance in the predisposition towards tuberculosis, is it wise to take great precautions in sterilising infants' foods? Would it not be well to accustom the baby to the tubercle bacillus by giving him a few with his feeds, or, at any rate, by not endeavouring by every means to eliminate the organism and prevent its access to the body. This, of course, is no new proposition, but it appears to be the logical conclusion of Professor Cummins's argument.

It would be interesting if Professor Cummins would state his views on this subject-we know that 6.5 per cent. of the 943 samples of milk examined in London last year contained tubercle bacilli; would this be a suitable means of immunising the children of London, or would the risk of mass infection be too great? I am, Sir, yours faithfully,

Weymouth-street, W., Nov. 5th, 1920.

G. E. BEAC MONT.

\section{TRANSPOSITION OF VISCERA.}

\section{To the Editor of THE LANCET.}

SrR,-A few months ago I discovered an interesting case of transposition of viscera during a routine inspection in one of our elementary schools. The case was that of a boy of 12 years whose apex beat and heart sounds were found on his right side. Percussion showed liver dullness on the left. He was X rayed at the Dundee Royal Infirmary by Dr. George Miller and a skiagram of his thorax was obtained which showed the heart and liver transposed. During the screening of the abdomen the fundus of the stomach was distinctly visible on the right side, and mouthfuls of a bismuth meal could be traced to the lower part of the stomach, well to the right of the middle line. The diagnosis was made of transposition of the viscera. The boy is perfectly healthy and has had no illness except measles in early childhood.-I am, Sir, yours faithfully,

CATHERINE KIRK,

Nov. 6th, 1920. Assistant M.O. to Dundee Education Authority.

\section{"THE RIGHT TO STRIKE."}

To the Eaitor of THE LANCET.

SIR,-I was extremely amused by the views of the Medical Secretary on my acting, the more so as I find I was apparently representing an official who in real life is represented by himself! He must forgive me therefore if I do not attach too high a value to an opinion which it would appear you did not ask him for, and which he becomes so sensibly confused over in that he mixes acting and authorship in a woeful mess. For after saying that I am "a futile person," which he thinks is not the author's intentions, he condemns me, "after listening to $m y$ inanities" (the italics are mine), to death, apparently for speaking the author's words! or does he think I make them up as I go along? Of one thing I am sure, and no doubt it occurred to him at once, and that is that he could have done it much better than I, and I hope this may solace him in his quieter moments. - I am, Sir, yours faithfully, Savage Club, Nov. 4th, 1920.

THE ACTOR.

** We do not quite understand our correspondent's letter. The communication to which he alludes was written by the Medical Secretary, while the criticism to which he takes exception referred to the actor who played the part of solicitor. Of course, the more inane the author's conception, the more does inanity become a virtue in the actor. We are sure our medical correspondent did not think he was criticising the acting in his recommendation that such a character as was presented would do well to shoot himself.-ED. L.

Wandsworth Borough Maternity Home,-This home was visited by H.M. the Queen on Nov. 6th. It has been handed over to the borough council, free of debt, as a memorial to the officers and men of the borough who died on service. It has been equipped on modern lines and will be apen to patients in a short time. The accommodation avail. The home will be maintained by the borough council, partly by patients' fees, ranging from $£ 1$ to $£ 4$ a week, partly out of the rates, and partly by grants from the Ministry of Health. 